\title{
Artigos
}

Vinicius Assis Couto

Universidade Federal de Minas Gerais, Belo Horizonte, MG, Brasil

Rafael Lacerda Silveira Rocha

Universidade Federal de Minas Gerais, Belo Horizonte, MG, Brasil

Ludmila Mendonça Lopes Ribeiro

Universidade Federal de Minas Gerais, Belo Horizonte, MG, Brasil

Andrea Maria Silveira

Universidade Federal de Minas Gerais, Belo Horizonte, MG, Brasil

\section{Intersetorialidade e ações de combate à violência contra a mulher}

Resumo: O artigo busca entender qual é a capacidade das redes construídas no âmbito da Lei
Maria da Penha e do projeto Mulheres da Paz para lidar com as temáticas da violência de
gênero. Para tanto, foram comparadas as percepções de atores-chave no que se refere aos
arranjos intersetoriais advindos da Lei Maria da Penha no município de Belo Horizonte e das
redes de proteção criadas através do projeto Mulheres da Paz, de Uberaba, bem como entrevistas
semiestruturadas com os beneficiários dessas ações. Conclui-se que ambas as ações
apresentam múltiplas dificuldades em se institucionalizarem como práticas intersetoriais e
parcerias sólidas com outras organizações que atendem mulheres vítimas de violência,
evidenciando que, apesar dos discursos acerca da participação e intersetorialidade, cada
vez mais presentes nas ações e políticas de enfrentamento à violência, na prática essas ações
tiveram pouca ressonância.
Palavras-chave: violência de gênero; Lei Maria da Penha; Mulheres da Paz; intersetorialidade 


\section{Introdução}

A violência doméstica e de gênero foi, por muito tempo no Brasil, um tema de menor importância para policymakers, identificada como uma questão que não gerava maiores debates no âmbito da sociedade civil. No entanto, essa situação vem mudando gradualmente nas últimas cinco décadas, com a criação de inúmeras associações não governamentais voltadas ao tema e a maior organização de movimentos e ativistas dos direitos das mulheres, que jogam luz sobre o problema e o colocam como uma pauta importante na agenda pública.

Um dos efeitos desse conjunto de ações foi o aumento de pesquisas que visam compreender e mensurar o tamanho do problema - o que nos permite, de certa maneira, entender as características e dimensões da violência contra a mulher. Em uma dessas iniciativas, o Mapa de Violência dedicou seu foco, no ano de 2012, aos homicídios de mulheres (Julio Jacobo WAISELFISZ, 2012). O anuário aponta que a taxa de homicídios de mulheres' apresenta um aumento praticamente contínuo, saindo de uma taxa de 2,3 mortes violentas para cada grupo de 100.000 mulheres no ano de 1980 para alcançar um patamar duas vezes maior, de 4,6, em 2010 , último ano da série. O estudo ainda destaca que a principal faixa etária das vítimas de violência letal é a compreendida entre 20 e 29 anos, algo distinto da violência contra os homens, concentrada na faixa entre 15 e 24 anos. Além disso, entre as mulheres, o percentual de vitimização por uso de arma de fogo, embora seja recorrente, é menor se comparado com os homicídios nos quais os homens são vítimas, indicando que as mulheres são mortas com facas e outros instrumentos disponíveis no ambiente doméstico, um dado importante quando complementado com a informação de que a maioria das mortes $(71,8 \%)$ ocorre dentro da residência da vítima, sendo que, em cerca de $28 \%$ das ocorrências, o autor do crime era cônjuge da vítima (WAISELFISZ, 2012).

Com dados coletados através de um survey aplicado um ano após a série histórica estudada por Waiselfisz, o Instituto Avon constatou que $80 \%$ da população conhece alguma mulher que já foi vítima de violência, sendo que $46 \%$ dos entrevistados entendem que tais violências decorrem de questões culturais, com ênfase no machismo (INSTITUTO AVON, 2011). Dois anos depois, ainda na esfera da violência doméstica, uma pesquisa conjunta feita pelo Data Popular, a convite do Instituto Patrícia Galvão, identificou que $70 \%$ dos entrevistados entendem que as mulheres sofrem mais violência dentro de casa do que fora dela. Além disso, cerca da metade dos entrevistados acredita que essa violência não é tratada da maneira devida pelos órgãos de justiça (DATA POPULAR e INSTITUTO PATRÍCIA GALVÃO, 2013).

Mesmo que parte significativa da população entenda a importância e a premência de políticas que diminuam a violência contra a mulher, um estudo recente desenvolvido pelo Instituto de Pesquisa Econômica Aplicada (IPEA, 2014) mostra que $89 \%$ dos entrevistados entendem que brigas entre casais devem ser resolvidas na esfera particular dos cônjuges. Ou seja, ainda é bastante difundida na população brasileira a percepção de que a violência doméstica não é um problema social, mas algo a ser resolvido "entre quatro paredes", sem a intervenção direta do Estado. Frente a estes dados é possível perceber a dimensão do problema da violência contra mulher e os desafios que sociedade civil e governos precisam superar.

A luta por um melhor sistema de proteção das mulheres vítimas de violência no Brasil se inicia nos anos 1970, conhecendo, ao longo das décadas, uma articulação de um número cada vez maior de atores preocupados com a divulgação e tematização do

${ }^{1}$ Taxa de mulheres assassinadas por grupo de cem mil mulheres. 
problema. Neste sentido, governos federal e estadual foram impelidos a implementar uma série (ainda que espaçada) de ações voltadas para o enfretamento da violência contra a mulher no Brasil. A primeira delas, elaborada ainda na década de 1980, foi a criação de Delegacias Especializadas ao Atendimento à Mulher, mais conhecidas como DEAMs. A constituição da primeira DEAM, em São Paulo, em 1985, foi uma vitória de grupos feministas locais junto ao governo paulista, que terminou sendo reproduzida em outras regiões do país (Paula STUKER, 2016). O intuito destas delegacias foi oferecer um atendimento diferenciado em um momento delicado, em função dosconstrangimentos e impedimentos que as mulheres historicamente encontravam ao denunciar a violência vivenciada para um corpo policial geralmente insensível à situação sofrida (CEPIA, 2000).

Entretanto, foi apenas na década de 2000 que o Estado brasileiro criou iniciativas efetivamente focadas na prevenção à violência contra as mulheres. O marco institucional dessas tentativas foi a fundação, no ano de 2003, da Secretaria de Política para as Mulheres (SPM), vinculada diretamente à Presidência da República. A Secretaria surgiu com o objetivo de fazer a articulação e coordenação de políticas para mulheres perante as outras esferas, assim como de exercer a tarefa de incorporar a perspectiva de igualdade de gênero no Poder Executivo Federal. Entre as diversas ações que contam com a atuação direta da SPM, destaca-se a Central de Atendimento à Mulher (Ligue 180), criada no ano de 2005 e que funciona como uma instância de orientação e acolhimento à mulher vítima de violência. Segundo o balanço anual da Central de Atendimento, até 2014, foram realizados mais de 485 mil atendimentos, sendo que $11 \%$ destes foram para relatar a vitimização de violência (SPM, 2014).

Contudo, é no ano de 2006 que surge o principal instrumento de combate à violência contra a mulher, a lei 1 1.340/06, também conhecida como "Lei Maria da Penha". A lei surge como uma conquista dos movimentos feministas (Cecília MacDowell SANTOS, 2010) e tornase uma resposta ao ineficiente tratamento dado ao problema pelas DEAMs, representando:

...uma ruptura com o escopo restritivo do conteúdo das denúncias acolhidas nas DEAMs, condicionadas na ordem da violência doméstica, sem, no entanto, compreender a dinâmica e complexidade dos conflitos interpessoais que caracterizavam o cotidiano das mulheres (Lourdes Maria BANDEIRA, 2009).

A Lei Maria da Penha representa, neste sentido, uma mudança na perspectiva, por propor entender e lidar com a violência contra mulheres. Outrora vista, no máximo, como uma questão de polícia, a violência contra as mulheres agora se coloca em outro patamar pelo Estado, que entende a necessidade da criação de articulações entre diversos órgãos públicos no intuito de tecer redes de proteção e prevenção, posto que, mais do que um caso de polícia, a violência de gênero é um problema social.

Compartilhando este entendimento, a Secretaria Nacional de Segurança Pública (SENASP) lançou, em 2007, o Mulheres da Paz como um dos quatro projetos ${ }^{2}$ constituintes do Programa Nacional de Segurança Pública com Cidadania (PRONASCI). De acordo com a Lei 11.530 , de 24/10/2007, que institui o PRONASCI, o projeto Mulheres da Paz visa à redução da violência nos chamados "territórios vulneráveis" por meio da "adoção de mecanismos

2 Os outros três projetos são Reservista-Cidadão, Bolsa-Formação e o Proteção de Jovens em Território Vulnerável - Protejo. A partir de 2012, os projetos Mulheres da Paz e Protejo foram reunidos em um único convênio, de forma que os municípios não pudessem executar os projetos isoladamente, em uma tentativa da SENASP de maximizar os resultados esperados e o uso de recursos públicos. Definiu-se que fossem articuladamente implementados em um mesmo território. A unificação dos convênios também institucionalizou o papel das Mulheres da Paz, não apenas frente às violências contra a mulher, mas como principal foco de captação do público alvo do Protejo. 
de valorização e reconstituição dos vínculos sociais", ou seja, é uma ação do governo federal com foco na prevenção da violência, que articula a política de segurança com ações de natureza social em âmbito municipal. Neste sentido, sua implementação depende do estabelecimento de um convênio entre a SENASP e o município, que define o território para a implementação do projeto, assim como fornece o apoio e a estrutura para a formação e atuação das mulheres. Estas são selecionadas nas comunidades para atuarem localmente como multiplicadoras nos debates acerca da cultura de paz e prevenção da violência, e articuladoras da rede de instituições locais, mobilizando os órgãos componentes na medida que as situações e demandas surjam no cotidiano da comunidade, particularmente aquelas que envolvem mulheres e jovens em situação de risco.

Este artigo tem como objetivo analisar em que sentido as instâncias governamentais conseguiram convergir para ações articuladas, assim como entender qual é a amplitude e capacidade das redes construídas para lidar com as temáticas da violência de gênero no âmbito da aplicação da Lei Maria da Penha e da implementação do projeto Mulheres da Paz. Para tanto, optamos por comparar os arranjos intersetoriais advindos da Lei Maria da Penha no município de Belo Horizonte e as redes de proteção criadas através do projeto Mulheres da Paz em Uberaba, ambas cidades de Minas Gerais. Foram utilizadas como fonte de dados entrevistas semiestruturadas com os mais diversificados operadores e beneficiários envolvidos nas ações. Através das percepções de atores-chave, o artigo busca reconstruir as redes institucionais com ênfase nas suas relações, capacidades e fraquezas para cumprir a proposta de tratar a violência contra a mulher de forma mais ampla.

\section{Mudança de perspectiva, redes e intersetorialidade}

"Crimes praticados contra as mulheres", "violência doméstica" ou mesmo "violência de gênero" são os termos mais comuns para caracterizar um mesmo fenômeno criminal que envolve a subjugação da mulher, apenas pelo fato de ela ser do sexo feminino, perante um homem, que, como visto, geralmente é uma pessoa próxima à vítima. Entretanto, esse fenômeno também possui elementos culturais, certa aceitação social e outras características que dificultam a identificação e erradicação de tais práticas. Além disso, a complexidade de identificar e analisar este fenômeno criminal é potencializada por suas diversas esferas de existência, posto que, diferentemente de outros tipos de crimes, a violência contra as mulheres não é sempre física, abarcando também a violência moral, psicológica, verbal e, não raro, uma confluência de todas estas formas. Dada a multiplicidade de formas do fenômeno criminal, deve-se entender esse tipo de violência como uma atividade complexa, no sentido definido por Edgar Morin (2000):

Complexus significa o que foi tecido junto; há complexidade quando elementos diferentes são inseparáveis constitutivos do todo (como o econômico, o político, o sociológico, o psicológico, o afetivo, o mitológico), e há um tecido interdependente, interativo e inter-retroativo entre o objeto de conhecimento e seu contexto, as partes e o todo, o todo e as partes, as partes entre si. Por isso a complexidade é a união entre a unidade e a multiplicidade. (MORIN, 2000).

Entender a violência contra as mulheres como uma ocorrência complexa impõe, necessariamente, um tratamento específico quando o objetivo é controlar e reduzir a incidência de tal fenômeno. Para além da criminalização, é necessário um esforço coletivo dos diversos órgãos - governamentais e intergovernamentais - que, de alguma maneira, estão envolvidos nessa dinâmica multifacetada. Dessa forma, propostas de articulações entre redes institucionais e ações intersetoriais tornam-se formas privilegiadas de políticas 
públicas voltadas para a temática da violência de gênero, especialmente, a que ocorre em âmbito doméstico.

A intersetorialidade das políticas públicas pode ser entendida como uma forma de interligação de agências e atores, "onde as ações sociais são compostas por diferentes tipos de intervenção, pertencentes a diferentes tipos de políticas" (VIANNA, 1998, p. 25). Parte-se do princípio de que o Estado não é mais o único responsável pelo bem-estar dos cidadãos, já que não exerce mais o controle total da implementação das políticas públicas. Pela lógica da intersetorialidade, estabelecem-se parcerias com ONGs, organizações religiosas, associações comunitárias e os próprios beneficiários das políticas. Como apontam Brena O'Dwyer Spina da Rosa Machado e Thamires de Lima Silva (2014), esta descentralização da implementação de políticas públicas torna o compartilhamento de responsabilidades um elemento crucial para o desenvolvimento das políticas sociais, em um processo de integração de Estado e Sociedade, dada a abertura de vias para a participação da sociedade civil na execução dessas políticas.

Segundo Carla Bronzo (2007), o tema da intersetorialidade ainda possui ambiguidades e ausência de clareza em sua definição, não sendo possível, por vezes, separá-lo de outros conceitos como, por exemplo, transversalidade. Mesmo assim, há um consenso entre os estudiosos da área no qual a intersetorialidade é entendida como um quesito importante de uma série de inovações na esfera da gestão pública. Tais inovações são implantadas como forma de superar uma gama de problemas sociais com os quais a gestão tradicional consegue lidar cada vez menos, como a forte hierarquização e a burocratização. Luciano A. Prates Junqueira $(1999,2004)$ entende que a intersetorialidade torna-se uma perspectiva importante para o combate dos problemas sociais, dada sua visão integrada acerca do próprio problema, e, consequentemente, para a busca por suas soluções. Nesse sentido, a ação intersetorial torna-se realidade em práticas coletivas construídas através de articulações de instituições e pessoas, que, por sua vez, "permitem pensar na ideia de rede como uma possibilidade de "reconstruir a sociedade civil" (JUNQUEIRA, 2004).

Pensar a constituição de redes como forma de possibilitar e facilitar ações é uma conclusão lógica em uma proposta intersetorial. Karine Yanne de Lima Pereira e Solange Maria Teixeira (2013) entendem que o trabalho em rede, nas políticas sociais, é uma forma de legitimação de uma nova maneira de se fazer proteção social, enquanto Maria do Carmo Brandt Carvalho e Maria Ferreira da Rosa Guará (1995) argumentam que o conceito de rede se apresenta como um tópico estratégico na administração pública, ao estabelecer vínculos horizontais de interdependências de instituições. Fica evidente que a estratégia do trabalho em rede nas políticas públicas, como abordagem intersetorial é, antes de tudo, uma forma de dividir não apenas as demandas, mas também as responsabilidades entre as instituições.

A temática da intersetorialidade surge não apenas no projeto Mulheres da Paz, mas como proposta da própria SENASP desde a sua fundação, em 1997. A Secretaria tem como algumas de suas principais competências promover a integração dos órgãos de segurança pública e a interface de ações com organismos governamentais e não governamentais. Soma-se a tais atribuições, propor financiamento aos órgãos estaduais e municipais engajados na elaboração e implementação de planos e programas integrados de segurança pública que objetivem controlar fatores específicos geradores de criminalidade e violência, bem como estimular ações sociais de prevenção da violência e da criminalidade (BRASIL, 2006). É evidente, dentre suas diversas atribuições, o caráter de articulação da SENASP, encontrado, especificamente, no PRONASCl, que contava com intervenções integradas entre o governo federal, estados e municípios para cumprir as 94 
ações propostas no programa, cabendo destacar a abordagem intersetorial em algumas políticas voltadas para a contribuição municipal na segurança pública (para além apenas da formação das Guardas Municipais), que reconhecem as cidades como lócus privilegiado para a implementação de políticas sociais preventivas, como os projetos Mulheres da Paz e Protejo (Luiz Eduardo SOARES, 2007).

Nesse sentido, o PRONASCI foi articulado em torno de duas categorias principais: as Ações Estruturais e os Programas Locais. O primeiro grupo envolve eixos temáticos como a modernização das instituições de segurança pública e do sistema prisional, valorização dos profissionais de segurança pública, enfrentamento à corrupção policial e ao crime organizado, em ações que mobilizam atores de atuação menos territorializada, como a Força Nacional de Segurança Pública, Polícia Rodoviária Federal, além de iniciativas como a Campanha do Desarmamento e a construção de centros de reabilitação para agressores condenados na Lei Maria da Penha. Já o segundo conjunto dos Programas Locais é formado por ações de base nos denominados "Territórios de Paz", como os Gabinetes de Gestão Integrada Municipal, Conselhos Comunitários de Segurança Pública e os projetos Proteção de Jovens em Território Vulnerável (Protejo) e Mulheres da Paz.

A Secretaria de Políticas para as Mulheres (SPM) também se propôs a abordar o tema da violência contra as mulheres no contexto da intersetorialidade na última década, fortalecendo redes institucionais e pensando o tema de forma multifacetada. Um exemplo dessa abordagem seria a criação, cinco anos depois da publicação da Lei Maria da Penha, do Pacto Nacional de Enfrentamento à Violência contra as Mulheres, que reforça a ideia de intersetorialidade e redes afirmando que sua missão é:

Induzir, articular e coordenar a elaboração de protocolos, fluxos, procedimentos e normatização dos serviços em articulação com o Sistema Único de Saúde, Sistema Único de Assistência Social, do Sistema Único de Segurança Pública, Poder Judiciário e Ministério Público (BRASIL, 2011).

É inegável que, nas últimas décadas, a percepção acerca da violência contra a mulher passou por profundas mudanças no Brasil, deixando de ser um assunto da esfera privada para ser caso de polícia, até chegar a uma perspectiva intersetorial de prevenção. A questão que se coloca é se a intersetorialidade e a atuação em redes conseguem se desenvolver na prática, especificamente na aplicação da Lei Maria da Penha e no Projeto Mulheres da Paz.

\section{A Lel Maria da Penha}

O ano de 2006 tornou-se uma data emblemática para operadores, pesquisadores e ativistas que se dedicam a trabalhar com a questão da violência contra as mulheres. Aprovada nesse ano, a Lei 11.340/2006, popularmente conhecida como Lei Maria da Penha, tornou-se um marco legal e simbólico no combate à violência sofrida por mulheres, principalmente no âmbito domiciliar.

Aproximadamente dois anos foi o tempo que separou a propositura da Lei Maria da Penha e a sua aprovação. Intermediado pela Secretaria Especial de Políticas para Mulheres (SPM), o projeto de lei que chegara ao Congresso Nacional no final do ano de 2004, foi promulgado pela Presidência da República em agosto de 2006 e contou com o apoio e pressão política de diversos movimentos e agremiações feministas, que trabalharam conjuntamente para que o projeto de lei fosse sancionado (Valéria PANDJIRJIAN, 2007 e Cecília Maria SARDENBERG et al, 2015).

A Lei Maria da Penha, já na sua criação, foi cercada de grande expectativa $e$ cobertura midiática, o que garantiu sua ampla divulgação e ressonância entre diversos

6 Revista Estudos Feministas, Florianópolis, 26(2): e45859 
segmentos sociais. Entende-se que o principal motivo de tantos "holofotes" foi o seu ineditismo de tratar da violência doméstica contra mulheres, um problema social de enormes dimensões e que, até aquele momento, era largamente menosprezado, inclusive pelo Estado. Nesse sentido, a Lei Maria da Penha foi, e ainda é, a principal iniciativa legal no sentido de proteger as vítimas e penalizar autores, "colocando a colher" em uma esfera outrora praticamente intocável. Desta forma, ela representa um marco na luta pela prevenção e punição da violência contra as mulheres, assim como na busca do reconhecimento pleno de seus direitos.

Com um novo arcabouço jurídico, a Lei Maria da Penha visava conferir maior rigor nas medidas punitivas e mais eficácia nos mecanismos de prevenção à violência. Como afirmam Rodrigo Ghiringhelli de Azevedo e Fernanda Bestetti de Vasconcellos (2012), a adoção da lei se dá em um contexto de descontentamento com o tratamento oferecido pelo Poder Judiciário à violência contra a mulher, posto que, por quase uma década antes da sua adoção, a maioria dos crimes dessa natureza era encaminhada nos Juizados Especiais Criminais (JECrim). Criado por meio da Lei 9.099/95, o JECrim, como o próprio nome sugere, consiste em um juizado para além da esfera ordinária do Judiciário, cujo intuito foi dar celeridade aos desvios menos graves, tentando garantir maior eficiência ao sistema. Assim, como informa o artigo 60 da lei supracitada, o "Juizado Especial Criminal, provido por juízes togados ou togados e leigos, tem competência para a conciliação, o julgamento e a execução das infrações penais de menor potencial ofensivo...". Com o funcionamento do JECrim, os crimes envolvendo violência doméstica, entendidos até então como crimes de menor potencial ofensivo, eram, na maioria das vezes, enviados para esse juizado. No entanto, dado o caráter conciliatório do mesmo, sua busca de celeridade e sua incapacidade de lidar efetivamente com o tema da violência doméstica e de gênero, o funcionamento do JECrim acabou gerando, como efeito adverso, a banalização das ocorrências desses tipos de vitimização.

Obviamente, apenas uma parcela das vítimas de violência doméstica busca ajuda formal, em decorrência de uma gama variada de barreiras institucionais e dificuldades culturais de relatá-la. Assim, àquelas mulheres que, apesar de inúmeros obstáculos, chegavam a impetrar ações contra seus agressores, restava o descrédito de ver seus algozes recebendo penas insignificantes, comumente substituídas pelo pagamento de cestas básicas. Por outro lado, para os agressores, a decisão reiterava a percepção de que o ato cometido era algo de menor importância e, por isso, passível de reincidência, se ele assim o desejasse. Tal percepção pode ser resumida na emblemática frase transcrita nos estudos de Guita Grin Debert e Marcella Beraldo de Oliveira (2007) na qual o agressor afirma: "Eu tenho então que pagar uma cesta básica? Se eu soubesse que era tão barato bater na minha mulher, teria batido mais vezes".

A Lei Maria da Penha veio como uma resposta legal a essas distorções. Primeiramente, no seu artigo 41 , a lei retira a violência doméstica contra a mulher da competência do JECrim, isto é, a lei 9.099/95. A Lei Maria da Penha também aumentou a pena máxima por lesões para três anos e três meses (artigo $44^{\circ}$ ), se essa "for praticada contra ascendente, descendente, irmão, cônjuge ou companheiro, ou com quem conviva ou tenha convivido, ou, ainda, prevalecendo-se o agente das relações domésticas, de coabitação ou de hospitalidade". Ela aumenta, assim, a punição para autores de lesões advindas de violência doméstica. Ainda, para melhor lidar com a temática, a lei prevê a criação de Juizados especializados em tal tipo de violência.

A Lei Maria da Penha previu um arranjo melhor e mais específico do Poder Judiciário para lidar com a matéria. Entretanto, mais que uma mudança legal, trata-se de entender a violência de gênero em novas bases, buscando vincular a punição ao desvio com iniciativas 
de prevenção. Nesse sentido, como afirma Wânia Pasinato (2015), a lei surge com importantes propostas, como:

\begin{abstract}
...o reconhecimento da violência baseada no gênero como violação de direitos humanos, constituindo um novo paradigma no ordenamento jurídico brasileiro, rompendo com a lógica da criminalização como remédio para acabar com a violência contra as mulheres. $E$, também, a ampliação da definição de violência para abarcar a violência física, sexual, psicológica, patrimonial e moral, pois cada uma dessas categorias abrange um conjunto igualmente amplo de comportamentos e ações que vão além do que se encontra previsto no Código Penal, alertando para a complexidade da violência baseada no gênero (PASINATO, 2015).
\end{abstract}

Para que o paradigma proposto pela Lei Maria da Penha ganhasse efetividade, saindo da forma abstrata da lei para se tornar uma ferramenta de combate e prevenção da violência, novos arranjos institucionais foram imprescindíveis. Em um cenário em que a própria lei indica a necessidade de ações articuladas entre a união, estados, municípios e instituições não governamentais, ideias explicitadas anteriormente, como ações articuladas em rede e práticas intersetoriais, ganharam relevância, sendo muitas vezes vistas como as únicas opções para a garantia da eficácia e da efetividade da lei em questão.

Para as instituições formais que já se dedicavam ao combate de violência contra as mulheres, como a Polícia Civil, tribunais de Justiça, Ministério e Defensoria Pública, a Lei Maria da Penha previu novos procedimentos com o objetivo de delinear melhor suas atribuições. Mas, mais que novas atribuições a esses atores, a lei aumenta a participação de outras esferas que lidam com o tema, orientando a articulação entre assistência social, área da saúde, varas de famílias, entre outras (PASINATO, 2015). Ou seja, ainda que a lei não disponha, necessariamente, sobre a criação de uma rede de serviços sociais, a "sua necessidade está implícita na aplicação da abordagem integral para o enfrentamento à violência, posto que nenhum serviço tenha condições de dar tal atendimento sozinho" (PASINATO, 2010, p. 24), dado que as medidas protetivas apenas podem funcionar como proteção à mulher se essa for acolhida, orientada e, sobretudo, amparada pelo Estado e outros serviços não estatais.

\title{
O projeto mulheres da paz
}

O projeto Mulheres da Paz, criado em 2007 pela SENASP como uma das ações constituintes do Programa Nacional de Segurança Pública com Cidadania (PRONASCI), trabalha com os temas da violência e mulher em uma perspectiva distinta, já que suas beneficiárias não são, necessariamente, vítimas de violência de gênero, mas atuam como agentes em sua identificação e prevenção (dentre outras modalidades de violência, como a perpetrada contra crianças e adolescentes) em suas respectivas comunidades. O desenho do Mulheres da Paz tem inspiração nos movimentos e associações de mães e visa mobilizar as mulheres dos territórios atendidos para atuarem como uma espécie de "agente comunitário de prevenção à violência", ao mesmo tempo institucionalizando lideranças comunitárias locais. Ademais, potencializa os esforços governamentais de enfrentamento da criminalidade, prevenção da entrada de jovens no mundo do crime e promoção de uma cultura de paz.

Neste sentido, as Mulheres da Paz, embora sejam as beneficiárias diretas do projeto, atuam como polos disseminadores de um discurso institucional em suas comunidades, não sendo, portanto, seu público-alvo. Este é composto pela comunidade como um todo, com atenção especial aos jovens com idade entre 15 a 24 anos, que sejam egressos do 
sistema prisional ou se encontrem em situação de rua, famílias expostas à violência urbana e mulheres em situação de violência doméstica e de gênero (BRASIL, 2008).

A criação do Projeto Mulheres da Paz é coerente com um modelo de intervenção social que, no Brasil, vem conferindo grande centralidade à implementação das políticas públicas voltadas às mulheres, seja como clientes dos programas de transferência de renda, seja como operadoras de programas governamentais de base local (Maxine MOLYNEUX, 2006; Bila SORJ, Carla GOMES, 2011). Esta participação das mulheres nos programas sociais brasileiros incorpora várias concepções de identidade de gênero. Uma dessas identidades valoriza o modelo tradicional de família, visto como um pilar para a construção de redes de segurança para as famílias pobres. Neste caso, os atributos tradicionalmente associados às mulheres, por exemplo, a vocação para o cuidado e a agregação das famílias colocam-se como virtudes a serviço das políticas de distribuição de renda, enfrentamento da pobreza e redução da vulnerabilidade social.

No caso do enfrentamento da violência, os movimentos de mães contribuíram para o fortalecimento da percepção que associa mulheres, maternidade e não violência, o que alimentou uma série de iniciativas governamentais e não governamentais de mobilização das mulheres para projetos e campanhas contra a violência, dentro e fora do âmbito doméstico. O projeto Mulheres da Paz, inicialmente, fundou-se na possibilidade de institucionalizar os movimentos de mães, atraindo-os para potencializar os esforços governamentais de prevenção da entrada de jovens no mundo do crime e promoção de uma cultura de paz.

Contudo, a Secretaria de Políticas para as Mulheres (SPM) identificou, na modelagem inicial do projeto, o fortalecimento da imagem "naturalizadora" de mães cuidadoras, à qual ela se opôs, defendendo que o projeto deveria promover o empoderamento das mulheres e a incorporação dos homens (SORJ, GOMES, 2011). Parte dessas sugestões foi absorvida no texto final do PRONASCl, que, no artigo $8^{\circ}$ da Lei $n^{\circ} 11.707$, agrega aos objetivos iniciais as alterações recomendadas pela SPM, explicitando, no texto legal, a tensão mãe versus mulher, como pode ser verificado a seguir:

O trabalho desenvolvido pelas Mulheres da Paz tem como foco:

I - a mobilização social para afirmação da cidadania, tendo em vista a emancipação das mulheres e prevenção e enfrentamento da violência contra mulheres; e

II -a articulação com jovens e adolescentes, com vistas à sua participação e inclusão em programas sociais de promoção da cidadania e na rede de organizações parceiras capazes de responder de modo consistente e permanente às suas demandas por apoio psicológico, jurídico e social (BRASIL, 2008).

Este formato está alinhado com uma concepção de participação que valoriza a presença das mulheres pobres no espaço público como forma de empoderamento, um elemento essencial ao projeto de mudança das relações de gênero, que se inicia na transformação pessoal, passa pela vida familiar e expande para o território em que vivem e atuam. Esta lógica orientou os cursos de capacitação do Mulheres da Paz rumo à incorporação de temas como violência familiar, sexualidade, direitos e liderança comunitária, valorização da autoestima e autodesenvolvimento, contribuindo, assim, para a superação de modelos tradicionais de feminilidade e para a construção de uma nova subjetividade. Este modelo calcado na ideia do empoderamento ainda está em sintonia com uma concepção de política pública que entende que, para transformar, é preciso mudar o indivíduo, o que se faz muito mais por meio da capacitação do que pelas mudanças estruturais. Este modelo valoriza o protagonismo como "elo de conexão entre os 
níveis micro e macrossociais, e confere à atividade de educação/capacitação uma importância central no desenho do programa Mulheres da Paz" (SORJ, GOMES, 2011).

A descrição do trabalho das Mulheres da Paz evidencia sua atuação como vetor de um discurso acerca da cultura de paz, afirmação da cidadania, como uma espécie de posto avançado de entrada para a rede de instituições estabelecidas no município. Por sua vez, para viabilizar esta ação transformadora das Mulheres da Paz em seu território, os municípios devem organizar uma capacitação inicial para as beneficiárias selecionadas, que em geral tem duração total de 48 horas, ${ }^{3}$ divididas em módulos com temáticas variadas.

Apesar da autonomia dada pela SENASP aos municípios para dar forma às ações, houve grande consonância dos temas que compuseram a capacitação inicial em Uberaba, com o restante da literatura sobre o Mulheres da Paz, com a inclusão de tópicos como cidadania, juventude, direitos humanos, violência de gênero, Lei Maria da Penha, cultura de paz, envolvimento com álcool e drogas (SANTOS \& SILVEIRA, 2015; SORJ \& GOMES, 2011) Após a capacitação inicial, as Mulheres da Paz começam a atuar nas comunidades, principalmente através das visitas às famílias em "situação de risco social". Essa ação tem como resultado relatórios com demandas e encaminhamentos para a equipe técnica do projeto e para a rede de instituições parceiras. Além das visitas, o projeto pressupõe a participação das Mulheres da Paz em fóruns locais, grupos de trabalho e demais ações comunitárias realizadas no território, com a orientação de articularem os demais atores da rede de proteção social com as demandas trazidas pelas famílias.

Nesse período de atuação das Mulheres da Paz, as participantes continuam recebendo capacitação, mas em um formato mais esparso e pontual, em geral com encontros semanais ou quinzenais. Durante todo o período de participação, ou seja, desde o início da capacitação inicial até o final do convênio, as Mulheres da Paz recebem uma bolsa mensal de $\mathrm{R} \$ 190,00$, vinculada à realização das visitas e entrega dos relatórios devidamente preenchidos. ${ }^{4}$

Como ressaltam Santos \& Silveira (2015), o formato adotado pelo Mulheres da Paz está profundamente alinhado à concepção de participação que valoriza a presença das mulheres oriundas de comunidades pobres no espaço público como forma de empoderamento. Tanto o investimento no indivíduo, através de cursos e capacitações, quanto a valorização de sua autoestima e capacidade como agente de transformação exprimem a lógica através da qual se orienta o projeto Mulheres da Paz: em oposição às grandes reformas e transformações estruturais, a mudança é buscada através do empoderamento do indivíduo e de sua participação qualificada nos espaços de sua comunidade, atuando, portanto, como intermediário nas dinâmicas micro e macrossociais.

\section{Intersetorialidade e atuação em rede na prática}

Apresentadas as ações que serão analisadas e o arcabouço teórico acerca da intersetorialidade como principal estratégia adotada nos últimos anos para lidar com a questão da violência contra a mulher, o foco volta-se, agora, para entender como estas redes entre as instituições efetivamente operam quando acionadas frente a um caso de violência de gênero.

\footnotetext{
${ }^{3}$ Como a SENASP permite bastante flexibilidade no que se refere ao formato das capacitações, alguns municípios preferem dar ênfase ao período de formação das Mulheres da Paz, como é o caso de São Bernardo do Campo/SP, onde o curso inicial tem duração de 96 horas, e de Santa Luzia/MG com 150 horas (Santos \& Silveira, 2015).

${ }^{4}$ Novamente, estamos nos referindo ao desenho geral do projeto. Contextos específicos podem apresentar alterações em função de suas demandas locais. Um exemplo disso é o município de São Bernardo do Campo/SP, onde, após uma longa avaliação da atuação das Mulheres da Paz, a obrigatoriedade de doze visitas a famílias por mês como critério de permanência no projeto foi abolida.
} 
A pesquisa empreendida no ano de 2014 na capital mineira buscou entender a efetividade das medidas protetivas da Lei Maria da Penha. ${ }^{5}$ Para tanto, entrevistou diversos operadores das redes de enfretamento e atendimento. Focalizando esforços no eixo segurança-justiça da rede, foram entrevistados 14 atores, dentre juízes, delegadas lotadas na DEAM, defensores públicos, promotores e demais atores que compõem o corpo psíquicosocial dessas instituições.

A primeira constatação feita pela pesquisa é que o discurso de um trabalho que envolve diversas instituições, criando uma efetiva rede de combate e acompanhamento, é um quase unívoco entre os operadores. Nesse sentido, em maior ou menor grau, observa-se uma interiorização do discurso da necessidade do trabalho intersetorial, proposto pelas políticas públicas nacionais discutidas acima. Também há o entendimento de que a constituição da rede deve visar à conexão de agências outras, além daquelas que atuam no eixo segurança-justiça. Assim, embora existam setores municipais e ONGs participando da rede, é comum a alegação de que a rede deveria agregar outras instituições:

A gente sente necessidade, inclusive isso foi uma questão que a gente discutiu esses dias com um Juiz, a nossa ideia é que essa rede precisa ser mais ampla, muitas vezes a gente resvala na questão da saúde, da ação social (Setor técnico do Judiciário).

Observa-se, para além do discurso, que as instituições pesquisadas possuem "vontade" de que o trabalho seja realizado em rede. Assim, pequenas iniciativas, como participar de reuniões, são executadas e vistas como grandes transformações na cultura de isolamento das instituições:

Tanto a Polícia Militar quanto a Polícia Civil compõem essa rede que existe em Belo Horizonte, que é uma rede completamente horizontalizada, voluntária, de órgãos que têm alguma atividade voltada para a violência doméstica (Polícia Militar).

A gente tem também um trabalho extrajudicial, que é um trabalho de articulação com os demais atores que trabalham com a questão da violência doméstica. A gente participa de reuniões da rede, então tem esse trabalho de articulação institucional e parceria institucional com a sociedade civil ... (Defensoria).

Entretanto, o problema ocorre em um momento posterior às reuniões, isto é, o obstáculo está em como traduzir para a prática a vontade de trabalhar de forma intersetorial. Conforme argumenta Bronzo (2007), a intersetorialidade exige mais do que uma singela conexão ou associação de órgãos. Neste sentido, mais que fazer parte do fluxo de processo, as instituições necessitam criar uma cultura objetivando o trabalho coletivo e integrado. Ao contrário do uso da rede desde essa perspectiva, procurando potencializar a construção de novas práticas e conceitos, o que se observa na rede estabelecida em Belo Horizonte é seu uso de forma procedimental e mecânica.

A gente tem contatos com a rede quando a gente precisa encaminhar essa mulher para algum serviço da rede, ou quando ela já é atendida em outro serviço e a gente precisa trocar impressões sobre o caso. (...) Houve um tempo em que nós participávamos mais dessas reuniões da rede e, mensalmente, ia um representante do Setor Técnico para essas reuniões. Acontece que nós estamos em um momento de volume de trabalho que nós não estamos mais em condições de participar de discussões da rede, então a gente aciona quando precisa de algum serviço (Setor Técnico do Judiciário).

O uso da rede de forma procedimental é tão forte que algumas instituições acabam criando vínculos coesos com alguns órgãos, em detrimentos de outros, apenas por terem

${ }^{5}$ Pesquisa financiada em parceria estabelecida em acordo de cooperação internacional por meio de carta de acordo firmada entre a Secretaria Nacional de Segurança Pública, o Programa das Nações Unidas e PUC-RS. 
mais contato no fluxo de processo. Assim, privilegiando interações que possivelmente já ocorreriam à revelia da existência da rede, por vezes, as instituições entendem processos rotineiros como atuação em rede:

Dos atores da rede, o que mais a gente trabalha é a Polícia Militar, porque eles têm o PVD (Programa de Violência Doméstica), então a gente trabalha muito com eles. Às vezes chega uma ocorrência aqui, a Polícia Militar conduz a vítima e o autor, e eu gosto de conversar com os policiais militares, porque eles estão na rua e estão vendo o que está acontecendo (DEAM).

Em outros momentos, a inexistência de ações relevantes organizadas de forma intersetorial, prevalecendo atos procedimentais, induz as instituições a perceberem a precariedade da rede da qual participam. Desta forma, não foi difícil ouvir dos entrevistados avaliações ruins do seu funcionamento:

A lei é nova, eu acho que ainda falta ainda muita coisa, falta funcionamento efetivo na rede, falta amparar essa mulher que realmente é vítima de violência, que está completamente desestruturada em função dessa situação de violência (Setor Técnico do Judiciário).

Fazer um trabalho de rede, porque a gente fala muito em rede, mas essa rede atua de forma precária. (Defensoria).

O principal motivo apresentado para explicar a precariedade do funcionamento do trabalho intersetorial e da constituição das redes é a ausência de estrutura das organizações. Neste sentido, a falta de atores para lidar com ações que vão além daqueles atos procedimentais que compõem a rotina dos operadores é o discurso mais ouvido.

A gente está tentando criar uma rede (...). Só que, nesses dias, deu uma paralisada, porque ela está instalando a $16^{a}$ Vara e é aquele negócio, está faltando computador, servidor. (Juiz 1).

Do ponto de vista legal a lei é bacana, o que falta é estrutura. A estrutura é deficiente, é só você ver o volume de processos nessas Varas. (Setor Técnico do Judiciário).

Tem um monte de coisas que a gente pode fazer. Na Delegacia de Mulheres, por exemplo, tem pouco efetivo, muitas vezes não consegue ouvir o homem, não consegue intimar o homem, então seria interessante ampliar as estruturas. Tudo está funcionando de uma forma muito precária, apesar de todo mundo trabalhar muito (Juiz 2).

Outro fator elencado pelos entrevistados como um impedimento na articulação intersetorial é a existência de diferenças entre as instituições. Isto é, quando se comparam as instituições, cada uma possui uma estrutura e cultura específicas, o que seria esperado em uma política que pretende integrar saberes diversos para o enfrentamento da violência doméstica contra a mulher. Assim, as formas de entender, administrar e executar tarefas são diferentes. Contudo, dada à cultura de hierarquia e homogeneidade de saberes dentro das agências que deveriam ser interligadas, os entrevistados têm a percepção de que tais singularidades atrapalham a realização das ações em rede.

A gente tem assento nessa rede e a gente vai tentando se aproximar e estabelecer parcerias, estabelecer trocas entre a atividade que é realizada lá e a nossa atividade. Não é simples, porque a gente está falando de dinâmicas diferentes, de estruturas diferentes, mas a gente vem tentando se aproximar cada vez mais (Polícia Militar).

Esse argumento é interessante porque contradiz um dos pilares da ideia de intersetorialiedade, que é perceber que a idiossincrasia das instituições é uma forma de contribuir para o entendimento complexo do problema a ser tratado. Dessa maneira, o

12 Revista Estudos Feministas, Florianópolis, 26(2): e45859 
trabalho articulado apenas faria sentido potencializando as experiências e formas particulares de contribuições das instituições.

Por fim, um último motivo apontado para a precariedade da rede é a inexistência de um juizado próprio para lidar com a violência contra a mulher. De fato, a cidade de Belo Horizonte possuía, à época da pesquisa, três varas especializadas, estando em processo a implantação da quarta vara. Entretanto, não há uma sinalização da criação desse juizado, muito embora, na maioria dos discursos apresentados pelos atores participantes da rede, nas entrevistas ou na reunião da própria rede, a questão seja um consenso como forma de efetivar a articulação em rede.

O Juizado representa uma mudança de cultura jurídica. Vamos trabalhar em rede, isso que é o Juizado. Funciona no mesmo espaço e, em princípio, de forma articulada: todos os órgãos que tratam da questão da violência doméstica, a Justiça, a Defensoria, o Ministério Público, a Polícia e o setor técnico (Psicologia e Serviço Social). Está todo mundo no mesmo lugar: é exatamente essa ideia de lugar que vai prestar um serviço à mulher que é interessante, e o fato de nós termos varas criminais compartimentadas mostra que nós não temos essa visão de trabalho em rede (Defensoria).

Os obstáculos enumerados e a constatação da precariedade da rede acabam por levar os entrevistados a entenderem que a rede (por mais que se observem a boa vontade dos atores e os diversos avanços conquistados) não consegue executar de forma satisfatória ações capazes de garantir um complexo acompanhamento da mulher vitimada.

O sistema não está completo e acabado. A gente poderia acompanhar, depois de um ano, com um setor técnico maior. Acompanhar as medidas, poder trabalhar mais o agressor também. Conseguir acompanhar uma vez por mês, pelo menos, sobre o que está acontecendo, se o ciclo de violência acabou (Juiz 2).

Assim, pelo menos no eixo segurança-justiça, há o entendimento de que a rede não funciona de forma articulada. Salvo algumas exceções, o trabalho das instituições na rede se restringe a reaplicar os procedimentos que lhe cabem por lei. Por sua vez, ações que vão além das atribuições legais, ações que possam ser entendidas como boas práticas, por exemplo, reuniões com grupos de agressores dentro da DEAM, ou mesmo o monitoramento de alguns agressores feito pela Polícia Militar através do PVD, são práticas criadas, vinculadas e executadas por determinada instituição, sem que haja, necessariamente, uma articulação entre os órgãos.

O cenário vivido pelo projeto Mulheres da Paz em Uberaba, no que tange às ações intersetoriais, não se diferencia muito dos elementos apontados para a rede de instituições envolvidas na aplicação da Lei Maria da Penha, embora algumas particularidades do projeto possam ser apontadas. Estas similaridades são mencionadas nas entrevistas realizadas no ano de 2014 com cinco beneficiárias do projeto e quatro integrantes da equipe de coordenação local do Território da Paz.

As participantes do projeto Mulheres da Paz têm como objetivos primários a mobilização comunitária e a articulação da rede de organizações parceiras para atender os casos por elas encaminhados. Cabe, portanto, às Mulheres da Paz percorrer as casas da comunidade e, graças à sua legitimidade e ao contato prévio com os vizinhos, identificar situações de violências contra mulheres e encaminhá-las à rede local, especialmente intuições de saúde, assistência social e de justiça. Neste sentido, a boa atuação das Mulheres da Paz combina a sensibilidade para identificar os casos de violência doméstica, o conhecimento da rede local e dos serviços disponíveis no município para cada demanda específica, com o fato de elas próprias serem mulheres, o que possibilitaria um vínculo com 
as vítimas e uma escuta apurada acerca da violência sofrida:

Está, assim, confiando na gente, está se mostrando, se abrindo. A gente teve instruções nos cursos, de ajudar essas mulheres, instruindo, encaminhando elas para a pessoa certa, conduzir. Então, eu acho muito interessante, assim, esse trabalho é um trabalho muito bonito; envolve amor, escolher mulheres para fazer o trabalho: é interessante nessa área, por quê? Mulher se abre com mulher, tem confiança em mulher. Se tivesse um homem e nós adentrássemos dentro de um lar e a mulher tivesse passando por isso [situação de violência], ela não ia ter a mesma liberdade de se abrir conosco (Mulher da Paz, Uberaba).

Destaca-se também o processo de seleção das participantes do projeto: priorizar mulheres com histórico de atuação comunitária prévia e, portanto, maior legitimidade frente aos moradores. Este é um dos pontos de inovação no desenho do projeto Mulheres da Paz: a política pública se beneficia ao selecionar mulheres com trajetórias de liderança comunitária, e não raro de vitimização semelhante à sofrida pelo público que visa atender, mas qualifica a atuação comunitária destas mulheres, inserindo-as na rede de instituições parceiras locais e no debate acerca de seus direitos e de como efetivamente garanti-los:

Eu já trabalhava para a igreja, só que eu não tinha a instrução que nós temos hoje. Nós não tínhamos esse amparo de lei, esse amparo que nós temos hoje. É interessante chegar tendo o amparo, porque, às vezes, a gente chegava dentro de um lar, a situação era agressão. Aí a gente tinha que fazer o quê? "Não, Jesus vai te ajudar!" Só que nós precisamos buscar essa força do Senhor, mas precisamos ter um amparo. Hoje nós temos aquela firmeza de que uma lei vai lá para acudir aquela mulher, se nós levássemos alguém que vai ajudar ela de forma diferente. Tem alguém. Eu tenho alguém que vai vir acudir. Mas antes não, [a mulher] sofria, apanhava dentro de casa, porque não tinha uma ajuda (Mulher da Paz, Uberaba).

Além da capacitação das mulheres selecionadas, tanto a inicial como a continuada, o acompanhamento de sua atuação na comunidade compõe o cerne do trabalho da equipe técnica, formada por psicólogos, advogados, assistentes sociais e pedagogos. Estes auxiliam as Mulheres da Paz com as demandas com as quais estas se deparam no cotidiano da comunidade, orientando-as em situações de maior complexidade e, principalmente, monitorando a forma como os encaminhamentos são feitos por elas para a rede de instituições parceiras e mantendo contato com estas instituições. Nesse intuito, o próprio desenho do projeto define que as Mulheres da Paz devem fazer um número mínimo de 12 visitas domiciliares por mês e, ao identificarem situações de violência de gênero, assim como casos de abuso de álcool e drogas ilegais, além de privações ${ }^{6}$, elas devem preencher um relatório descrevendo as especificidades do caso, e o(s) encaminhamento(s) feito(s) para a rede de instituições parceiras, que é recebido pela equipe técnica para que o encaminhamento seja acompanhado.

Nesse desenho, a Mulher da Paz localiza a demanda. Depois, durante a visita domiciliar, faz a escuta da vítima de violência e estabelece um vínculo com esta, muitas vezes com base em seu histórico de atuação comunitária ou experiência com situações de violência de gênero. Este atendimento geralmente se transforma em um encaminhamento à rede de instituições locais, que passa a ser supervisionado pela equipe técnica. A Mulher da Paz identifica a demanda e aciona a rede de parceiros, enquanto a equipe de coordenação local do Território da Paz oferece suporte a esta ação e institucionaliza o

\footnotetext{
${ }^{6}$ Como por exemplo: crianças em idade escolar não matriculadas, idosos e pessoas com necessidades especiais em situação de abandono, demandas de atendimento médico e odontológico, e famílias elegíveis para bolsas e auxílios estatais, mas que não os estejam recebendo, etc.
}

14 Revista Estudos Feministas, Florianópolis, 26(2): e45859 
vínculo - até então um encaminhamento pontual -, buscando, junto aos envolvidos, uma solução conjunta para o caso. Neste processo, solidifica-se a parceria entre as instituições, propiciando um somatório de recursos, dispositivos para a ação e reflexão na rede de atores participantes.

Essa sequência de passos nem sempre ocorre como o esperado, no município de Uberaba. As entrevistas com as Mulheres da Paz, assim como com a equipe técnica, evidenciam o entrave que significa o encaminhamento para a rede. As Mulheres da Paz identificam as demandas, estabelecem o vínculo com a pessoa atendida e a encaminham para a rede parceira local. No entanto, uma série de fatores, como a sobrecarga dos serviços que compõem essa rede, o frágil vínculo dessas instituições com o projeto Mulheres da Paz, ou a demora em responder às demandas encaminhadas, produzem uma ruptura no fluxo do projeto e, em alguma medida, um esgarçamento na rede de instituições parceiras. Por sua vez, a lentidão ou dificuldade da rede de instituições parceiras de atender os casos encaminhados pelas Mulheres da Paz gera uma sobrecarga de trabalho para a equipe técnica do projeto, que passa a tentar acompanhar e agilizar o atendimento de mais de uma centena de encaminhamentos mensais pulverizados em uma rede municipal, no caso de Uberaba, pouco articulada e com baixo conhecimento acerca do projeto, como apontam as falas a seguir:

Eu cheguei esses dias em um local, no postinho, sabe? Eu fui no postinho de saúde, cheguei lá e falei o seguinte: "gente, eu gostaria de saber como é o andamento do postinho para levar a programação do PSF [Programa Saúde da Família], porque eu estou trabalhando no projeto Mulheres da Paz, e eu gostaria de conhecer mais onde eu vou estar, e onde vocês trabalham em relação a ginecologista, a psicóloga, para eu já saber e levar para as meninas do projeto Mulheres da Paz". Agora, um órgão público do município, e eles não sabiam, não estavam preparados para nos receber, imagina os encaminhamentos... (Mulher da Paz, Uberaba).

O problema é como ela falou, às vezes são demandas que a gente não tem retorno. Então a gente fica assim, "e se a pessoa ficar brava comigo?". (...) Um dia um falou comigo, aquele negócio, "isso é só conversa, história para boi dormir, não tem isso, não" (Mulher da Paz, Uberaba).

A dificuldade da rede de lidar com os encaminhamentos, por sua vez, pode gerar uma impressão de que a falha de execução é do projeto Mulheres da Paz, ou pior, ser personalizada na figura da participante que estabeleceu o vínculo e fez o encaminhamento da demanda. Em Uberaba, a legitimidade e o histórico de mobilização comunitária das participantes, características tão caras a esta política pública de prevenção e atendimento a vítimas de violência de gênero, são colocadas em jogo na esfera pública local ao se associarem a um projeto que, efetivamente, não consegue sustentar plenamente a atuação em rede que propõe.

\section{Considerações finais}

O artigo teve como objetivo analisar a aplicação da Lei Maria da Penha e a implementação do projeto Mulheres da Paz, sob a perspectiva da articulação em rede para o desenvolvimento de suas ações e propostas para combater a violência contra a mulher nos municípios de Belo Horizonte e Uberaba.

Na cidade de Belo Horizonte, a busca da aplicação da Lei Maria da Penha através do fortalecimento das redes de atendimento alcançou desenvolvimento parcial na criação e atuação de algumas instituições. Para além dos abrigos ou DEAMs, a rede de atendimento às mulheres em situação de violência deve ser compreendida por "centros de referência 
da mulher, defensorias da mulher, promotorias da mulher ou núcleos de gênero nos Ministérios Públicos, juizados especializados de violência doméstica e familiar contra a mulher" (BRASIL, 2011 ). Tomando tal parâmetro, entende-se que, em Belo Horizonte, a prescrição é cumprida de forma fragmentada. Assim, a criação de centros de referência e de núcleos específicos da promotoria e defensoria ${ }^{7}$ contrastam com um trabalho compartimentado em varas, dada a inexistência de um juizado especializado.

Por outro lado, a questão é entender em que medida as instituições já existentes na rede são capazes de exercer um trabalho coletivo a ponto de a intersetorialidade ser considerada realmente uma rede. Neste quesito, a incapacidade de realizar um atendimento e acompanhamento amplo à vítima, ou mesmo, a inépcia e, por muitas vezes, a impossibilidade estrutural de executar ações que vão além das atribuições formais ou procedimentais, mostram que boa parte das instituições que compõem a rede de atendimento não consegue estabelecer ações intersetoriais suficientemente conectadas a ponto de criar articulações perenes entre as instituições.

No caso de Uberaba, pelo próprio desenho do projeto Mulheres da Paz, que tem no encaminhamento das demandas um norte de atuação, a prática intersetorial foi incentivada tanto em relação às Mulheres da Paz como em relação ao corpo da equipe técnica dos Territórios da Paz. Mas, à medida que estes encaminhamentos para a rede de instituições parceiras não eram atendidos de maneira satisfatória - devido à sobrecarga dos aparelhos do município e/ou baixa articulação das instituições que atuam sobre o mesmo território a legitimidade do projeto e, principalmente, das mulheres que nele atuam pode ser prejudicada. A descentralização do processo de implementação de políticas públicas torna o compartilhamento de responsabilidades um elemento crucial no desenvolvimento das políticas sociais dentro deste novo modelo. Mas, a partir do momento em que se lida com atores locais da comunidade como agentes de uma política pública naquele território, cabe questionar o quanto desta transferência de responsabilidade por parte do Estado para a mulher líder comunitária contribui para a baixa eficácia da política, haja vista que, dessa forma, as externalidades negativas são transferidas para os atores locais que dela participam em detrimento das agências do Estado. No caso do projeto Mulheres da Paz em Uberaba, as próprias moradoras e lideranças dos bairros em que o projeto foi implementado questionam a efetividade desta iniciativa.

Desta forma, ambas as ações, aplicação da Lei Maria da Penha e implementação do projeto Mulheres da Paz, apresentam múltiplas dificuldades em se institucionalizarem como políticas intersetoriais e parcerias sólidas com outras organizações que se debruçam sobre a mesma temática, evidenciando que, apesar dos discursos acerca da participação e intersetorialidade, na prática estas noções têm pouca ressonância. As duas ações estudadas buscaram, de maneiras distintas, o trabalho em rede e a intersetorial, com efeitos também díspares. Na aplicação da Lei Maria da Penha, a ausência de uma rede estruturada coloca em risco a proteção plena da mulher, prevista em lei, posto que o não atendimento articulado e completo pode cercear as mulheres do exercício efetivo dos seus direitos, sejam eles a segurança, o respeito, a liberdade ou mesmo a dignidade. Em relação ao projeto Mulheres da Paz, a baixa articulação da rede local dificulta, ou, em alguns casos, inviabiliza, os encaminhamentos feitos pelas participantes, o que, como no caso da aplicação da Lei Maria da Penha, tem por consequência a falha no atendimento pleno da mulher vítima de violência de gênero. No entanto, devido ao desenho do projeto Mulheres da Paz, essa má articulação da rede de instituições também pode resultar na perda de

${ }^{7}$ Mesmo que essas atuem de forma limitada, o núcleo da Defensoria, por exemplo, não consegue acompanhar as vítimas em momentos importantes, como a audiência de consentimento de medida protetiva.

16 Revista Estudos Feministas, Florianópolis, 26(2): e45859 
legitimidade das agentes comunitárias, que, ao participarem como mobilizadoras em suas comunidades e porta de entrada para a rede parceira, podem, eventualmente, ser corresponsabilizadas por suas falhas frente ao público atendido pelo projeto.

\section{Referênclas}

AZEVEDO, Rodrigo Ghiringhelli de; VASCONCELLOS, Fernanda Bestetti de. "A Lei Maria da Penha e a administração judicial de conflitos de gênero: Inovação ou reforço do modelo penal tradicional?" Revista Dilemas, Rio de Janeiro, v. 5, n. 4 p. 549-568, out./nov./dez, 2012.

BANDEIRA, Lourdes Maria. "Três décadas de resistência feminista contra o sexismo e a violência feminina no Brasil: 1976 a 2006." 2009. Disponível em: http://repositorio.unb.br/ bitstream/10482/7289/1/ARTIGO TresDecadas.pdf. Acesso em 15/06/2015.

BRASIL. Lei $n^{\circ}$ 11.707, de 19 de junho de 2008. Altera a Lei no 11.530, de 24 de outubro de 2007, que institui o Programa Nacional de Segurança Pública com Cidadania - Pronasci. Disponível em: http://www.planalto.gov.br/ccivil_03/_ato2007-2010/2008/Lei/ L1 1707.htm\#art1. Acesso em 15/06/2015.

. Portaria n० 1.821, de 13 de outubro de 2006. Aprova o Regimento Interno da Secretaria Nacional de Segurança Pública - SENASP. Disponível em: http://www.justica.gov.br/suaseguranca/seguranca-publica/senasp-1/portaria_1821_senasp.pdf/@@download/file/ portaria_1821_senasp.pdf. Acesso em 15/06/2015.

Secretaria Especial de Políticas para Mulheres - SPM. Pacto Nacional de Enfrentamento à Violência contra as Mulheres. Brasília, 2011.

BRONZO, Carla. Intersetorialidade como princípio e prática nas políticas públicas: reflexões a partir do tema do enfrentamento da pobreza. In: XX CONGRESSO DO CENTRO LATINOAMERICANO DE ADMINISTRACIÓN PARA EL DESARROLLO - CLAD 12, Anais, Santo Domingo: CLAD, 2007. p. 1-39

CARVALHO, Maria do Carmo Brandt de; GUARÁ, Maria Ferreira da Rosa. Gestão municipal dos serviços de atenção à criança e ao adolescente. São Paulo: IEE PUC/SP-CBIA, 1995.

CIDADANIA, ESTUDO, PESQUISA, INFORMAÇÃO E AÇÃO (CEPIA). Violência contra a mulher: um guia de defesa, orientação e apoio. 2000. Disponível em http://www.cepia.org.br/ Textos_online/cartilha2000.pdf. Acesso: 28/08/2015.

DATA POPULLAR, INSTITUTO PATRÍCIA GALVÃO. Percepção da Sociedade sobre Violência e Assassinatos de Mulheres. São Paulo, 2013. Disponível em http:// agenciapatriciagalvao.org.br/wp-content/uploads/2013/08/ livro pesquisa_violencia.pdf. Acesso em 28/08/2015.

DEBERT, Guita Grin; OLIVEIRA, Marcella Beraldo de. "Os modelos conciliatórios de solução de conflitos e a 'violência doméstica'." Cad. Pagu, Campinas, n. 29, p. 305-337, dez. 2007.

INSTITUTO AVON. Pesquisa Instituto AVON/IPSON: percepções sobre a violência contra a mulher no Brasil. São Paulo: IPSON, 2011 . 17p. Disponível em; http://www.spm.gov.br/leimaria-da-penha/lei-maria-da-penha/pesquisa-avon-201 1.pdf. Acesso em 15/06/2015.

INSTITUTO DE PESQUISA ECONÔMICA APLICADA (IPEA). Sistema de Indicadores de Percepção Social. 2014. Disponível em: http://www.ipea.gov.br/agencia/images/stories/PDFs/SIPS/ 140327 sips_violencia_mulheres_antigo.pdf. Acesso em 28/08/2015.

JUNQUEIRA, Luciano A. Prāes. "A gestão intersetorial das políticas sociais e o terceiro setor." Saúde e Sociedade. São Paulo, v. 13, n. 1, p. 25-36, 2004.

"Descentralização, intersetorialidade e rede como estratégias de gestão da cidade." Revista FEA, São Paulo, v. 1, p. 57-72, nov. 1999. 
MACHADO, Brena O'Dwyer Spina da Rosa; SILVA, Thamires de Lima. "Mulheres da paz: um estudo de caso sobre as noções de empoderamento no contexto do investimento social." Revista Habitus: revista eletrônica dos alunos de graduação em Ciências Sociais - IFCS/ UFRJ, Rio de Janeiro, v. 12, n. 1, p.7-19, junho, 2014.

MOLYNEUX, Maxine. "Mothers at the service of the new poverty agenda: progresa/ oportunidades, Mexico's conditional transfer programme." Social Policy \& Administration, Chichester, v. 40, n. 4, p. 425-449, 2006.

MORIN, Edgar. Os setes saberes necessários à educação do futuro. São Paulo: Cortez, 2000.

PANDJIRJIAN, Valéria. "Maria da Penha: una mujer, un caso, una ley." Revista Informativa CLADEM, Lima, n. 09, año 06, p. 38-51. 2007.

PASINATO, Wânia. "Lei Maria da Penha Novas abordagens sobre velhas propostas. Onde avançamos?" Civitas-Revista de Ciências Sociais, Porto Alegre, v. 10, n. 2, p. 216-232, 2010.

"Oito anos de Lei Maria da Penha. Entre avanços, obstáculos e desafios". Revista Estudos Feministas, Florianópolis, v. 23, n. 2, maio, 2015.

PEREIRA, Karine Yanne de Lima; TEIXEIRA, Solange Maria. "Redes e intersetorialidade nas políticas sociais: reflexões sobre sua concepção na política de assistência social". Revista Textos Contextos, Porto Alegre, v. 12, n. 1, p. 114-127, 2013.

SANTOS, Cecília MacDowell. "Da delegacia da mulher à Lei Maria da Penha: absorção/ tradução de demandas feministas pelo Estado". Revista Crítica de Ciências Sociais. Coimbra, n. 89, p. 153-170, 2010.

SANTOS, Simone Maria dos; SILVEIRA, Andréa Maria. "Os desafios de um projeto de prevenção à violência e à criminalidade: Mulheres da criminalidade: o Mulheres da Paz em Santa Luzia/MG". Revista Estudos Feministas, Florianópolis v. 23, n. 1, p. 99-118, 2015.

SARDENBERG, Cecilia Maria Bacellar; GROSSI, Miriam Pillar. "Balanço sobre a lei Maria da Penha." Revista Estudos Feministas, Florianópolis, v. 23, n. 2, p. 497-500, 2015.

SOARES, Luiz Eduardo. "A Política Nacional de Segurança Pública: histórico, dilemas e perspectivas". Estudos Avançados, São Paulo, v. 21, n. 61, p. 77-97, 2007.

SORJ, Bila; GOMES, Carla. "O gênero da 'nova cidadania': o programa mulheres da paz". Sociologia \& Antropologia. Rio de Janeiro, v. 01/02, p. 147-164, 2011.

STUKER, Paola. 'Entre a cruz e a espada': significados da renúncia à representação criminal por mulheres em situação de violência conjugal no contexto da Lei Maria da Penha. Dissertação (Mestrado em Sociologia). 2016. Programa de Pós-Graduação em Sociologia do Instituto de Filosofia e Ciências Humanas da Universidade Federal do Rio Grande do Sul, Porto Alegre, RS, Brasil. 2016.

WAISELFISZ, Julio Jacobo. Mapa da violência 2012: Atualização: Homicídios de mulheres no Brasil. Brasília: Centro Brasileiro de Estudos Latino-Americanos, 2012. Disponível em http://www.mapadaviolencia.org.br/pdf2012/MapaViolencia2012_atual_mulheres.pdf. Acesso em 28/05/2015.

[Recebido em 26/07/2016, reapresentado em $30 / 08 / 2017$ e aceito em 25/09/2017]

Intersectoriality and Actions to Face Violence Against Women

Abstract: The article aims to understand the capacity of the networks built under the Maria da Penha Law and the Women of Peace project to deal with the issues of gender violence. For this purpose, the perceptions of key actors regarding the intersectoral arrangements arising from the Maria da Penha Law in the city of Belo Horizonte and the protection networks created through the 
Women of Peace project in Uberaba were compared, as well as semi-structured interviews with the beneficiaries of these actions. It is concluded that both actions present multiple difficulties in institutionalizing as intersectoral practices and strong partnerships with other organizations that meet women victims of violence. This evidences that despite the discourses about participation and intersectoriality increasingly present in the actions and policies that face with violence, in practice these actions had little resonance.

Keywords: Gender Violence; Maria da Penha Law; Mulheres da Paz; Intersectoral Actions

Vinicius Assis Couto (viniccouto@gmail.com/vinicius@crisp.ufmg.br) é doutorando em Sociologia, pesquisador do Centro de Estudos de Criminalidade e Segurança Pública (CRISP).

Rafael Lacerda Silveira Rocha (rafael.rocha@crisp.ufmg.br) é doutorando em Sociologia, pesquisador do Centro de Estudos de Criminalidade e Segurança Pública (CRISP).

Ludmila Mendonça Lopes Ribeiro (ludmila.ribeiro@gmail.com) é professora adjunta do Departamento de Sociologia (DSO) e pesquisadora do Centro de Estudos de Criminalidade e Segurança Pública (CRISP), ambos da Universidade Federal de Minas Gerais (UFMG). Suas principais publicações estão relacionadas a temas como funcionamento do sistema de justiça criminal; policiamento comunitário; efeitos da vitimização por crime na cultura da cidadania e políiticas de segurança pública.

Andrea Maria Silveira (andrea@crisp.ufmg.br) é professora Associada do Departamento de Medicina Preventiva e Social, e subcoordenadora do Centro de Estudos de Criminalidade e Segurança Pública (CRISP). Possui Graduação em Medicina pela Universidade Federal de Minas Gerais (1986), Mestrado em Sociologia e Doutorado em Ciências Humanas, ambos pela Universidade Federal de Minas Gerais (UFMG). Atualmente é Diretora Técnica do Hospital das Clínicas da UFMG e Professora Associada do Departamento de Medicina Preventiva e Social da Faculdade de Medicina da UFMG onde atua na graduação médica e no Mestrado Profissional em Promoção da Saúde e Prevenção da Violência. Atua ainda Programa de Pós-Graduação em Sociologia. Tem experiência na área de Saúde Coletiva, com ênfase nos temas: trabalho, saúde, prevenção e violência. 